\title{
Electrocardiographic Findings and Prognostic Value of Long QTe Interval in Acute Organophosphate Insecticide Poisoning
}

\author{
Ahmad A. El-Ebiary' ${ }^{1}$, Mohammed A. Soliman² and Essam M. Hafez ${ }^{3}$ \\ ${ }^{1}$ Department of Forensic Medicine and Clinical Toxicology, Faculty of Medicine, Tanta University, Tanta, Egypt. \\ ${ }^{2}$ Department of Internal Medicine, Alnahdah Hospital, Muscat, Oman. \\ ${ }^{3}$ Department of Forensic Medicine and Clinical Toxicology, Faculty of Medicine, El-Minia University, El-Minia, Egypt.
}

\begin{abstract}
Organophosphorus (OP) insecticides are one of the most important pesticides, and poisoning induced by them is a major global health problem with about 3 million intoxications and 300,000 deaths occurring worldwide every year. This study aimed to investigate the relevance of ECG findings and prognostic value of corrected QT (QTc) interval in acute OP poisoning cases. The study recruited 91 patients suffering from acute OP poisoning, who were admitted to Tanta University Poison Control Center over a period of two years (March 2013 - March 2015). ECG changes, QTc interval length, and the different outcomes of the patients were recorded including mortality, the need for endotracheal intubation and/or mechanical ventilation, the length of hospital stay, and the total amount of atropine and/or obidoxime administered. The higher need for intubation and assisted ventilation in patients with prolonged QTc compared to patients with normal QTc was statistically significant. The mortality rate in the long QTc group was not significantly different from that of the normal QTc group. Moreover, there was no statistically significant difference between the two groups regarding the length of hospital stay or the doses of obidoxime and atropine required to control the muscarinic signs and symptoms. However, the total atropine dose was significantly lower in survivors than non survivors. It could be concluded that QTc interval prolongation needs to be considered as a prognostic indicator in acute OP poisoning.
\end{abstract}

Keywords Organophosphorus poisoning; electrocardiography; prognosis; QTc interval.

\section{Introduction}

$\mathrm{O}$ rganophosphate pesticides poisoning is a major health problem in developing countries because they are easily accessible and used extensively in agriculture and other uses as well. In Egypt, organophosphate intoxication is a common cause of morbidity and mortality and represents more than $50 \%$ of insecticide poisoning (Ibrahim et al., 2011; Iyer et al., 2015).

Acute organophosphate poisoning is associated with three different clinical syndromes including acute cholinergic crisis, intermediate syndrome and delayed polyneuropathy. Acute cholinergic crisis results from inhibition of acetylcholinesterase enzyme, which is associated with muscarinic (bradycardia, bronchorrhea, bronchospasm, hypotension, diarrhea, abdominal cramps, miosis, hypersalivation), nicotinic (tachycardia, hypertension, skeletal muscles fasciculations and weakness) and central (tremor, seizures, coma, central respiratory depression) manifestations. Intermediate syndrome occurs 24 to 96 hours after acute OP poisoning, and following resolution of the cholinergic crisis. It is characterized by manifestations of proximal muscle weakness and cranial nerve palsies. Paralysis of the muscles of respiration leads to respiratory failure. Inhibition of neuropathy-target esterase results in delayed polyneuropathy, which is characterized by sensory impairment and weakness of peripheral muscles in the hands and feet. This can occur with chronic OP exposures or days to weeks following acute exposures (Kamanyire and Karalliedde, 2004; Eddleston and Clark, 2011). 
The evaluation of outcome is a key component of any health care system. There is an observed growing interest in medicine for measuring the severity of illness and predicting outcome in critically ill patients (Henderson, 2004). Even though the most common complication is the respiratory failure, cardiac complications may also occur after OP poisoning, and poison specialists often fail to fully recognize these complications, particularly complex ventricular arrhythmias that are commonly missed (Cha et al., 2014).

In Egypt, poisoning with OP pesticides is a common problem with high risk of mortality and morbidity. This emphasizes the importance of predicting mortality of these cases to allow proper resource allocation and to decide how aggressive the treatment should be. Previous research has shown that cholinesterase activity and serum $S$-glucuronidase levels correlate with severity and mortality rates in OP poisonings. However, these laboratory methods are not readily available and their usefulness remains debatable, which calls attention to the need for a clinically-based prognostic system. QTc prolongation and its relation to the prognosis of acute organophosphate poisoning was reported by a few studies (Shadnia et al., 2009; Yurumez et al., 2009; Akdur et al., 2010; Liu et al., 2012), and unfortunately with conflicting results. Hence, in the present study we aimed to assess the prognostic value of this clinical tool in acute OP poisoning patients. In addition, the relevance of other ECG changes and clinical outcomes regarding the prognosis were also evaluated.

\section{Patients and methods}

This study was conducted at Tanta University Poison Control Center, Tanta, Egypt. It was approved by our local Ethics Committee. A written informed consent was obtained from each patient on initial admission. All individual information was securely protected and available to investigators only, and all the data were analyzed anonymously.

\section{Eligibility criteria}

Over a period of two years (March 2013 - March 2015) a total of 91 patients (out of 165 patients assessed for OP intoxication) were included in this study. The diagnosis of acute OP poisoning was based on history of exposure, clinical manifestations including response to atropine and obidoxime (Toxogonin ${ }^{\circledR}$ ), and pseudocholinesterase activity. Patients who were medically treated for OP poisoning in any healthcare facility before admission, those younger than 18 years old, with ingestion or exposure to other substances in addition to the OP, with a past history of cardiac disease, or using medications that might be associated with QTc prolongation were excluded from the study.

\section{Management protocols}

All patients received standard treatment including patient resuscitation and decontamination (when indicated), along with administration of specific antidotes (Atropine: bolus dose of 2 to $5 \mathrm{mg} \mathrm{IV}$, repeated every 10 to 15 minutes until dryness of bronchial secretions was clinically evident, then atropine injections were given intermittently to patients as needed; Obidoxime $\left(\right.$ Toxogonin $^{\circledR}$ ): $250 \mathrm{mg}$ loading dose followed by $750 \mathrm{mg}$ every 24 hours) (Roberts and Aaron, 2007).

A complete clinical profile of each patient was obtained. The following data were recorded for each patient:

- History: age, sex, habits (smoking, alcohol consumption), mode of exposure, compound involved, time elapsed between exposure and admission to the hospital, and underlying diseases.

- Examination: complete physical examination including vital data such as heart rate (HR), respiratory rate (RR), blood pressure (BP), and temperature (T).

- Hypertension was defined as a blood pressure of 140/90 $\mathrm{mmHg}$ or more.

- Hypotension was defined as a blood pressure of less than $90 / 60 \mathrm{mmHg}$.

- Tachycardia was defined as a heart rate of 100 beats/min or greater.

- Bradycardia was defined as a heart rate of less than 60 beats/min.

- Investigations: electrocardiography (ECG), pseudocholinesterase (PChE), arterial blood gases $(\mathrm{ABG})$, complete blood count (CBC), and routine blood biochemistry including liver and renal functions, random blood sugar, and serum electrolytes.

- The different outcomes of the patients were recorded. These included mortality, the need for endotracheal intubation and/or mechanical ventilation, the length of hospital stay, and the total dose of atropine and/or obidoxime administered.

- The ECG recordings were obtained on admission before the administration of atropine. ECG analysis included the rate, rhythm, ST/T abnormalities, conduction defects and measurement of PR and QT intervals. The QT interval was corrected (QTc) according to the formula of Bazett (Bazett, 1920). QTc was considered prolonged when it was longer than 0.440 second (Baydin et al., 2007). Electrocardiographic records were conducted on a Cardiofax ECG machine (NIHON KOHDEN, ECG6511 , Japan), at $10 \mathrm{~mm} / \mathrm{mV}$ and $25 \mathrm{~mm} / \mathrm{s}$ paper speed. All ECGs were analyzed manually by two experienced observers who were unaware of other patient data.

\section{Statistical analysis}

Statistical presentation of the present study was conducted using the mean and standard deviation of values. Analysis of data was done by Chi-square test and student $t$-test using SPSS version 15 computer program. The level of statistical significance was set at $p$ value below 0.05 .

\section{Results}

The current study included 91 patients (69 males) diagnosed as acute OP poisoning. The age of the patients ranged from 18 to 60 years old with most patients (35 patients) falling in the age group 18-28 years, 21 patients for each of the age groups >28-38 and >38-48, 11 patients in the age group $>48-58$, and only 3 patients in 
the age group $>58$ years. Most patients (more than $82 \%$ ) were from rural areas. Exposure was accidental in 59 patients and intentional in 32 patients. Most cases (about $80 \%$ ) presented to the hospital within 6 hours. Among the study subjects 70 patients had a normal QTc interval and were placed in group A. The other 21 patients with QTc prolongation (> 0.440 seconds) were designated as group B. No statistically significant difference was noticed between the normal and prolonged QTc groups regarding age, gender, residence, mode of exposure, or delay time between exposure and admission (table 1).

Prolongation of QTc interval was the most common ECG abnormality that was seen in 21 patients $(23.1 \%)$, followed by sinus bradycardia (HR $<60$ beats/min), then sinus tachycardia (HR $\geq 100$ beats/min), and finally prolongation of PR interval ( $>0.2$ seconds) that was seen in only 3 patients (3.3\%). Hypertension (BP $\geq 140 / 90 \mathrm{mmHg}$ ) and hypotension (BP $<90 / 60$
$\mathrm{mmHg}$ ) were detected in $7.7 \%$ and $2.2 \%$ of patients respectively (table 2 ).

Compared to group A, patients in group B (with QTc prolongation) had higher incidences of mortality, need for intubation and assisted ventilation, longer duration of hospital stay, and they utilized higher doses of atropine and obidoxime. However, only the need for intubation and assisted ventilation were statistically significant when comparing both groups (table 3 ).

Three patients (3.3\% of the study participants) died by the end of this study, and they were all suicidal. To examine the role of variables on survival, the patients were divided into 2 groups; survivors and nonsurvivors (table 4). There was no statistically significant difference between the two groups based on age, gender, delay time, and duration of hospital stay. There was a statistically significant relationship between both groups regarding the mode of exposure and the dose of atropine administered during hospitalization.

Table 1. Demographic and toxicologic data. (Number $=91$ patients)

\begin{tabular}{|c|c|c|c|c|}
\hline & $\begin{array}{c}\text { Group A } \\
(\text { Normal QTc) } \\
(\mathbf{n}=\mathbf{7 0})\end{array}$ & $\begin{array}{c}\text { Group B } \\
\text { (Prolonged QTc) } \\
(\mathbf{n}=\mathbf{2 1})\end{array}$ & $P$ value \\
\hline \multicolumn{2}{|l|}{ Age, years } & $32.51 \pm 12.28$ & $38.52 \pm 11.89$ & 0.322 \\
\hline \multirow[t]{2}{*}{ Gender, n (\%) } & Male & $52(74.3)$ & $17(81)$ & \multirow[t]{2}{*}{0.531} \\
\hline & Female & $18(25.7)$ & $4(19)$ & \\
\hline \multirow[t]{2}{*}{ Residence, n (\%) } & Rural & $56(80)$ & $19(90.5)$ & \multirow[t]{2}{*}{0.269} \\
\hline & Urban & $14(20)$ & $2(9.5)$ & \\
\hline \multirow[t]{2}{*}{ Exposure, n (\%) } & Accidental & $45(64.3)$ & $14(66.7)$ & \multirow[t]{2}{*}{0.841} \\
\hline & Suicidal & $25(35.7)$ & $7(33.3)$ & \\
\hline \multicolumn{2}{|l|}{ Delay time, hours } & $5.41 \pm 1.73$ & $4.7 \pm 3.01$ & 0.657 \\
\hline
\end{tabular}

$n=$ number

Table 2. Distribution of cardiovascular findings among patients with acute OP poisoning on admission according to gender. (Number $=91$ patients $)$

\begin{tabular}{|l|c|c|c|c|c|c|}
\hline \multirow{2}{*}{} & \multicolumn{2}{|c|}{ Male } & \multicolumn{2}{c|}{ Female } & \multicolumn{2}{c|}{ Total } \\
\cline { 2 - 7 } & $\mathbf{n}$ & $\mathbf{\%}$ & $\mathbf{n}$ & $\mathbf{\%}$ & $\mathbf{n}$ & \% \\
\hline Prolonged QTc interval & 17 & 18.7 & 4 & 4.4 & 21 & 23.1 \\
\hline Prolonged PR interval & 3 & 3.3 & 0 & 0 & 3 & 3.3 \\
\hline Sinus tachycardia & 13 & 14.3 & 6 & 6.6 & 19 & 20.9 \\
\hline Sinus bradycardia & 18 & 19.8 & 2 & 2.2 & 20 & 22 \\
\hline Hypertension & 7 & 7.7 & 0 & 0 & 7 & 7.7 \\
\hline Hypotension & 2 & 2.2 & 0 & 0 & 2 & 2.2 \\
\hline
\end{tabular}

$n=$ number

Table 3. Comparison between patients with normal and prolonged QTc intervals regarding doses of atropine and obidoxime administered, mortality, need for intubation, need for ventilation and duration of hospital stay. (Number =91 patients)

\begin{tabular}{|l|l|l|l|}
\hline & $\begin{array}{c}\text { Group A } \\
\text { (Normal QTc) } \\
(\mathbf{n = 7 0 )}\end{array}$ & $\begin{array}{c}\text { Group B } \\
\text { (Prolonged QTc) } \\
(\mathbf{n = 2 1 )}\end{array}$ & P value \\
\hline Atropine dose, $\mathrm{mg}$ & $7.14 \pm 4.28$ & $9.23 \pm 5.07$ & 0.063 \\
\hline Obidoxime dose, g & $0.7 \pm 0.93$ & $0.92 \pm 1.01$ & 0.360 \\
\hline Mortality, n (\%) & $1(1.4)$ & $2(9.5)$ & 0.068 \\
\hline Intubation, n (\%) & $3(4.3)$ & $4(19)$ & $0.026^{*}$ \\
\hline Ventilation, n (\%) & $3(4.3)$ & $4(19)$ & $0.026^{*}$ \\
\hline Hospital stay duration, days & $2.35 \pm 1.65$ & $2.66 \pm 1.01$ & 0.604 \\
\hline
\end{tabular}


n=number, *Significant

Table 4. Comparison between survivors and dead cases regarding age, gender, mode of exposure, delay time, doses of atropine administered and duration of hospital stay. (Number $=91$ patients)

\begin{tabular}{|l|l|l|l|l|}
\hline \multicolumn{2}{|l|}{} & \multicolumn{1}{|c|}{$\begin{array}{c}\text { Survivors } \\
(\mathbf{n = 8 8})\end{array}$} & Nonsurvivors (n= 3) & P value \\
\hline Age, years & $33.53 \pm 12.35$ & $44.66 \pm 9.8$ & 0.127 \\
\hline \multirow{2}{*}{ Gender, n (\%) } & Male & $67(76.1)$ & $2(66.7)$ & 0.706 \\
\cline { 2 - 4 } & Female & $21(23.9)$ & $1(33.3)$ & \\
\hline \multirow{2}{*}{ Exposure, n (\%) } & Accidental & $59(67)$ & $0(0)$ & $0.017^{*}$ \\
\cline { 2 - 5 } & Suicidal & $29(33)$ & $3(100)$ & \\
\hline Delay time, hours & $5.17 \pm 1.15$ & $7.66 \pm 0.57$ & 0.488 \\
\hline \multicolumn{2}{|l|}{ Atropine dose, mg } & $7.37 \pm 4.32$ & $15.5 \pm 5.15$ & $0.004^{*}$ \\
\hline \multicolumn{2}{|l|}{ Hospital stay duration, days } & $2.35 \pm 2.38$ & $4.66 \pm 0.57$ & 0.098 \\
\hline
\end{tabular}

$n=$ number, *Significant

\section{Discussion}

The age of patients included in this study ranged from 18 to 60 years with a mean age of $32.51 \pm 12.28$ years in group A and $38.52 \pm 11.89$ years in group B. The majority of patients were in the age group 18-28 years and only 3 patients in the age group above 58 years. Likewise, Gannur et al. (2008) and Makwava Prakash et al. (2012) reported that the majority of acute OP poisoned patients were between 21 and 30 years. This could be explained by the wide spread and easy availability of $\mathrm{OP}$ compounds during working in agriculture and the lack of use of protective devices. Moreover, in Egypt working in agriculture is usually found among middle aged men, which means that workers of this age will be heavily exposed to OP compounds (Magauzi et al., 2011).

In this study, males were more frequently exposed to acute OP poisoning than females because males work in agriculture more than females. This was in the same line with Bertsias et al. (2004) and Lin et al. (2008) who studied the epidemiology of OP pesticide poisoning in Greece and Taiwan and reported a male prevalence in their research work. However, one study (Kara et al., 2002) found that the majority of the acute OP poisoned patients were females, which could be attributed to geographical and work pattern differences.

In the current study, the majority of patients were from rural areas (more than 82\%). Comparable findings were reported in other research work, which could be justified by the wide use of OP compounds in the rural agricultural society due to their low price (Gannur et al., 2008; Patel and Tekade, 2011).

Regarding the circumstances of acute OP poisoning, this study revealed that exposure was accidental in about two thirds of the cases. Farm workers might lack knowledge about safe use and practices for proper storage, preparation and disposal of pesticides (Gannur et al., 2008; Zyoud et al., 2010). This result was in accordance with Elgazzar et al. (2012) who reported that $65.5 \%$ of their study patients were accidentally exposed to OP compounds. Generally the suicidal attempts are always linked to the stressful atmosphere whatever the kind and source of the stress that may be marital, financial, employment or unemployment stresses (Jaga and Dharmani, 2007; Patel and Tekade, 2011). The low suicidal rate in the present study in relation to other studies might be attributed to religious prohibition of the suicidal act among Egyptians.

In the present study, the mean delay time in acute OP poisoned cases was less than 6 hours $(5.41 \pm 1.73,4.7 \pm 3.01$ hours in group $\mathrm{A}$ and $\mathrm{B}$ respectively) with no significant difference between both groups. A similar result was noticed by other researchers (Makwava Prakash et al., 2012). Rapid patient transfer to Tanta Poison Control Center might be due to its close vicinity to the surrounding rural areas, which represented the major source of this kind of poisoning.

Prolongation of QTc interval was the most common ECG abnormality reported, and it was seen in 21 patients $(23.1 \%)$. Comparable studies showed higher incidences (reaching up to 55\% of cases) of QTc prolongation among OP poisoned patients (Yurumez et al., 2009). Grmec et al. (2004) confirmed that a long QTc interval and a low Glasgow coma score in OP poisoned patients go along with higher numbers of intubations and worse outcomes. These patients had poor prognosis, and they had significantly higher rates of respiratory failure, ventricular premature contractions, and mortality compared to patients without QTc prolongation (Shadnia et al., 2009; Morteza et al., 2013). Likewise, the results of our study demonstrated that patients with QTc prolongation had higher incidences of intubation and need for assisted ventilation. In addition, the study revealed, although insignificant, higher mortality rates and longer duration of hospital stay among patients with QTc prolongation. Hence, the current study asserts an association between prolongation of QTc interval, the intensity of poisoning, and the prognosis of the patients. Although the exact mechanism by which OP induce cardiotoxicity is still uncertain, three phases of cardiac toxicity after exposure to OP have been described. An initial brief period of increased sympathetic activity associated with tachycardia and hypertension. This is followed by a prolonged period of cholinergic activity 
characterized by bradycardia, hypotension, ST-T changes, and life-threatening dysrhythmia. Finally, a longer phase may occur, during which a prolonged QT interval and polymorphic ventricular tachycardia can result in sudden death (Taromsari et al., 2013). The prolonged QT interval is caused by unequal sympathetic stimulation of myocardial cells, interactions with potassium channels and the $\mathrm{Na}^{+} / \mathrm{Ca}^{++}$exchanger in the myocardial cell membrane (Eddleston and Clark, 2011).

In this study 4 patients, which represents $19 \%$ of those with prolonged QTc interval had respiratory failure. This could have a great clinical significance owing to its frequency and the possibility of early intervention by endotracheal intubation in the out-ofhospital setting to prevent death. In this study, the occurrence of QTc prolongation was clinically correlated with the severity of intoxication. Patients with QTc prolongation had a higher incidence of intubation and assisted ventilation in comparison with patients without QTc prolongation. Three patients (3.3\%) died by the end of this study, and they were all suicidal. Intentional cases of poisoning are usually associated with exposure to higher doses of the poison, and this may explain the significantly increased doses of atropine needed to control their toxic manifestations seen in this study. On the contrary, Atli and colleagues (2013) found that five out of thirty nine patients included in their study died during the treatment. They found no significant relationship between ECG findings and the severity of OP poisoning. However, this study had a small sample size upon which no solid conclusion could be assumed.

Considering all factors, it could be concluded that QTc prolongation needs to be considered as a prognostic indicator in acute OP intoxications. It is recommended to keep in mind the importance of ECG as an easy bedside tool for initial assessment of patients with acute OP poisoning and to prepare for intensive care with readiness for endotracheal intubation and assisted ventilation for those with prolonged QTc. In addition, suicidal cases and those who were given large atropine doses should be considered as high risk patients and candidates for extensive supportive treatment. However, the small patient population and absence of serial ECG recordings can represent a potential source of error of the current study. In addition, this study was performed over a long period of time and included patients with different OP substances and variable methods of intoxication.

\section{Acknowledgements}

We are grateful to both Dr. Kamal Eldin Abdalmaged (Department of Cardiology, Faculty of Medicine, Tanta University, Egypt) for his valuable support in ECG reading and interpretation and Ms. Menna Ramadan $\left(6^{\text {th }}\right.$ year medical student, Faculty of Medicine, Menoufia University, Egypt) for her kind assist in reference citation.

\section{References}

Akdur O, Durukan P, Ozkan S et al., (2010): Poisoning severity score, Glasgow coma scale, corrected
QT interval in acute organophosphate poisoning. Hum. Exp. Toxicol. 29: 419-425.

Atli M, Sebe A, Ay M et al., (2013): The relationship between electrocardiographic changes, cholinesterase levels and mortality in acute organophosphate poisoning. Cukurova Med. J. 38: 181-188.

Baydin a, Aygun D, Yazici M et al., (2007): Is there a relationship between the blood cholinesterase and QTc interval in the patients with acute organophosphate poisoning? Int. J. Clin. Pract. 61: 927-930.

Bazett HC (1920): The time relations of the bloodpressure changes after excision of the adrenal glands, with some observations on blood volume changes. J. Physiol. 53: 320-339.

Bertsias G, Katonis P, Tzanakakis G et al., (2004): Review of clinical and toxicological features of acute pesticide poisonings in Crete (Greece) during the period 1991-2001. Med. Sci. Monit. 10: CR622-627.

Cha YS, Kim H, Go J et al., (2014): Features of myocardial injury in severe organophosphate poisoning. Clin. Toxicol. (Phila) 52: 873-879.

c): Insecticides: Organic Phosphorus Compounds and Carbamates. In: Hoffman RS, Nelson LS, Howland MA et al., eds. Goldfrank's Toxicologic Emergencies, $9^{\text {th }}$ edition. The McGraw-Hill, New York, pp. 1502-1504.

Elgazar FM (2012): Evaluation of different scoring systems in anticholinesterase pesticide poisoned patients. M.D. Thesis at Faculty of Medicine, Tanta University.

Gannur DG, Maka P and Narayan Reddy KS (2008): Organphosphorus compound poisoning in Gulbarga region-a five year study. Indian J. Forensic Med. Toxicol. 2: 1-6.

Grmec S, Mally S and Klemen P (2004): Glasgow Coma Scale score and QTc interval in the prognosis of organophosphate poisoning. Acad. Emerg. Med. 11: 925-930.

Henderson W (2004): APACHE: An evaluation. Paedagog. Hist. 40: 435-453.

Ibrahim MA, El Masry MK, Moustafa AA et al., (2011): Comparison of the accuracy of two scoring systems in predicting the outcome of organophosphate intoxicated patients admitted to intensive care unit (ICU). Egypt. J. Forensic Sci. 1: 41-47.

Iyer R, Iken B, Leon A (2015): Developments in alternative treatments for organophosphate poisoning. Toxicol. Lett. 233: 200-206.

Jaga K and Dharmani C (2007): The interrelation between organophosphate toxicity and the epidemiology of depression and suicide. Rev. Environ. Health 22: 57-73. 
Kamanyire $\mathrm{R}$ and Karalliedde L (2004): Organophosphate toxicity and occupational exposure. Occup. Med. 54: 69-75.

Kara IH, Güloğlu C, Karabulut A et al., (2002): Sociodemographic, clinical, and laboratory features of cases of organic phosphorus intoxication who attended the Emergency Department in the Southeast Anatolian Region of Turkey. Environ. Res. 88: 82-88.

Lin TJ, Walter FG, Hung DZ et al., (2008): Epidemiology of organophosphate pesticide poisoning in Taiwan. Clin. Toxicol. (Phila) 46: 794-801.

Liu S-H, Lin JL, Weng CH et al., (2012): Heart ratecorrected QT interval helps predict mortality after intentional organophosphate poisoning. PLoS One, 7: e36576.

Magauzi R, Mabaera B, Rusakaniko S et al., (2011): Health effects of agrochemicals among farm workers in commercial farms of Kwekwe district, Zimbabwe. Pan Afr. Med. J. 9: 26.

Makwava Prakash V, Odedara Ram V and Shah Harsh D (2012): Acute organophosphorus poisoning and clinical admission score association among patients admitted in emergency ward of a tertiary teaching hospital of medical college. J. Pharm. Biomed. Sci. 17: 1-5.

Morteza MM, Hossein K, Amirhossein M et al., (2013): Designing, construction, assessment, and efficiency of local exhaust ventilation in controlling crystalline silica dust and particles, and formaldehyde in a foundry industry plant. Arh. Hig. Rada. Toksikol. 64: 123-131.

Patel DJ and Tekade PR (2011): Profile of organophosphorus poisoning at Maharani Hospital, Jagdalpur, Chhattisgarh: A Three Years Study. J. Indian Acad. Forensic Med. 33: 102-105.

Roberts DM and Aaron CK (2007): Management of acute organophosphorus pesticide poisoning. BMJ. 334: 629-634.

Shadnia S, Okazi A, Akhlaghi N et al., (2009): Prognostic value of long QT interval in acute and severe organophosphate poisoning. J. Med. Toxicol. 5: 196-199.

Taromsari MR, Badsar A, Aghajankhah M et al., (2013): The Study of Electrocardiographic Findings in Patients with Organophosphate Poisoning. Iran. J. Toxicol. 6: 751-756.

Yurumez Y, Yavuz Y, Saglam H et al., (2009): Electrocardiographic findings of acute organophosphate poisoning. J. Emerg. Med. 36: 39-42.

Zyoud SH, Sawalha AF, Sweileh WM et al., (2010): Knowledge and practices of pesticide use among farm workers in the West Bank, Palestine: Safety implications. Environ. Health Prev. $\quad$ Med. 252-261.

\section{الملخص العربي}

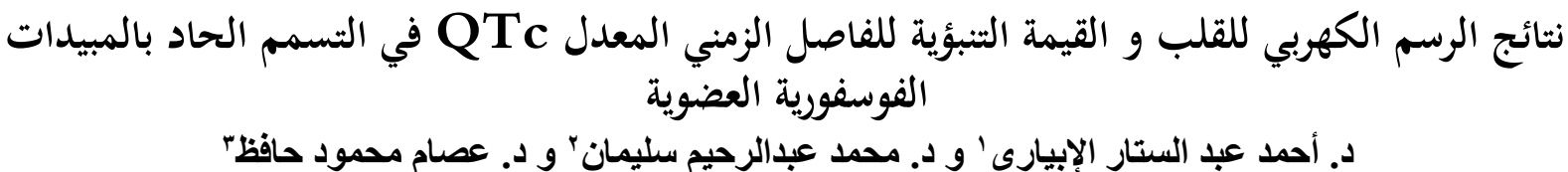

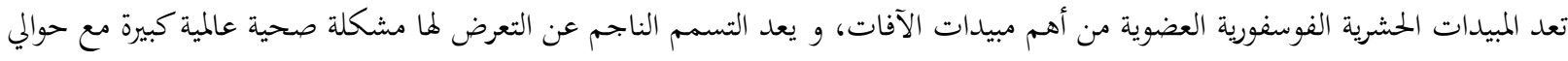
ب مليون حالة تسمم و . . . . . . م حالة وفاة سنويا.

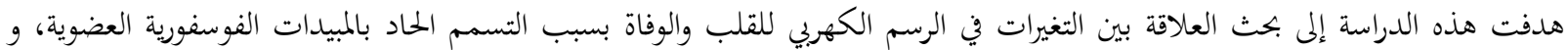

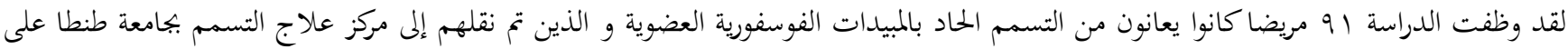

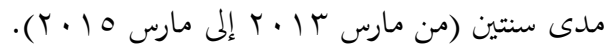

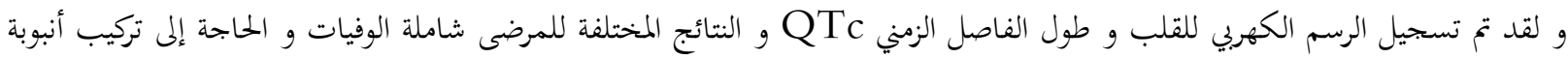

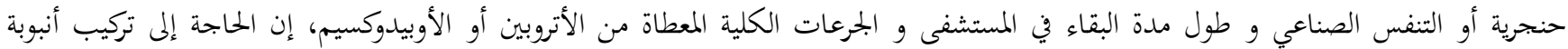

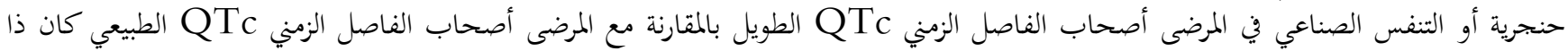

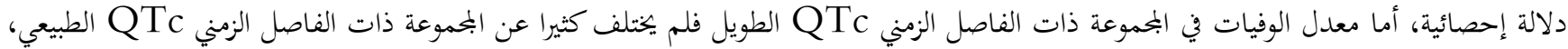

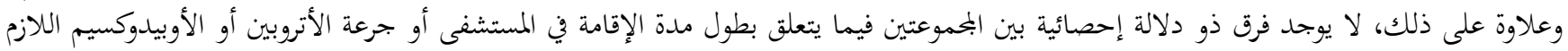

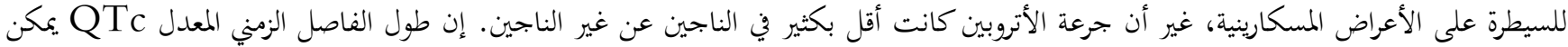
استخدامه كمؤشر تنبؤي في حالات التسمى الحماد بالمبيدات الفوسفورية العضوية.

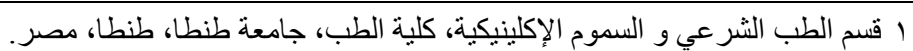

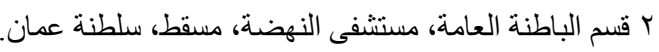

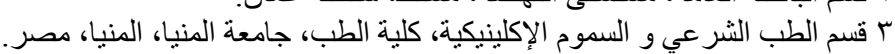

